\title{
Knowledge and Attitude of First Aid Skills among Health Science Students at Taibah University
}

Amal Salem Alhejaili ${ }^{\star}$ and Shorooq Abdulrazzaq Alsubhi

Department of Health Science, Taibah University, Saudi Arabia

*Corresponding author: Amal Salem Alhejaili, Department of Health Science, Taibah University, Saudi Arabia, E-mail: dr.amal-tu@outlook.com

Received date: May 07, 2016; Accepted date: Jun 14, 2016; Published date: Jun 22, 2016

Copyright: @ 2016 Alhejaili AS, et al. This is an open-access article distributed under the terms of the Creative Commons Attribution License, which permits unrestricted use, distribution, and reproduction in any medium, provided the original author and source are credited.

\begin{abstract}
Background: First aid is a simple step that done outside the hospital setting to save someone's life or prevent condition from worsening until arrival of health care providers.
\end{abstract}

Objective: Assess awareness about first aid knowledge among the female students of health science colleges before and after awareness presentation.

Methodology: A cross-sectional study was done among the female students of health science colleges through pre- and post- awareness assessments. Thirteen selected multiple choice questions about various emergency accidents were included in the questionnaire. The awareness presentation contained how to deal with the various emergency accidents was sent to the students via email and the comparison before and after the awareness presentation was analyzed.

Results: A total of 110 female students participated in this study. Only, 58 students completed the answers of the questionnaire to compare between pre- and post- awareness with the response rate of $52.7 \%$. There was a statistically significantly improvement in the best dealing with many situations such as checking for any hazards before doing first aid, loss of consciousness if victim can breathe or not, applying pressure in bleeding limb, supporting the fractured bone with a cushion, cooling the burn under cold water, putting the victim in safe place in convulsion and sit the patient and give him the medication in asthmatic attack.

Conclusion: This study showed inadequate knowledge about first aid among the female students. Health science students at Taibah University need first aid training program in their curriculum to improve the basic skill about it.

Keywords: First aid; Health providers; Emergency accidents

\section{Introduction}

First aid is a quick, temporary and simple step with minimal or no medical equipment that is done outside the hospital in order to save someone's life or at least relive pain and prevent condition from worsening until the arrival of health care providers that is the main aim of first aid [1-3].

The future health care providers in the community are students of health science colleges. First aid is not difficult, it needs a good attitude and a few simple steps with adequate knowledge and skills that make anyone deal with any accidents [1].

Health science student generally and medical student especially even in their early years of studying are expected by general public to know how to do first aid to an injured patient and save live.

In this study, the most common accidents that usually people face in their life were specified. Basic first aid in emergency of bleeding, choking, seizure, hypoglycemic attack, burns, fractures, nasal bleeding, poisoning, asthmatic attack and fainting should be known by everyone [3].

\section{Objective}

To evaluate the knowledge of first aid among female health science students at Taibah University before and after awareness presentation.

\section{Methodology}

This study was to assess awareness about first aid skills among the female students of health science colleges at Taibah University in AlMedina between November 2015 to February 2016. The selected health science colleges were College of Medicine, Nursery and Dentistry. This research was approved by the College of Medicine Research Council Ethical Committee of Taiba University [3].

The participants in this study were approximately 110 randomly chosen with ages ranging between 19 and 26 years [1]. A questionnaire was distributed to 110 female students through "collective data collection" and 110 female students participated and the postawareness which was "emailed" questionnaire distributed to 110 students and the participated were 58 students. The questionnaire includes 19 questions ranging between 5 open ended questions and 14 closed ended which is multiple choice questions on topics about burn, bleeding, choking, fracture, nasal bleeding, seizure, poisoning, asthmatic attack, hypoglycemic attack and loss of consciousness. The awareness program was an educational material which was provided to 
Citation: Alhejaili AS, Alsubhi SA (2016) Knowledge and Attitude of First Aid Skills among Health Science Students at Taibah University. J Gen

Page 2 of 5

students along with the questionnaire. This material included information regarding first aid and an appropriate way to deal with it in each emergency case. The data were coded, entered and processed on a computer using SPSS "Version 19, IBM Corp, United States". Data was summarized using mean, standard deviation and range. A chi square test was used to analyze categorical data and paired' $\mathrm{t}$ ' test was used for variable analysis. $P$ value of $<0.05$ was considered to indicate a statistical significance [3].

\section{Result}

A total of 110 female students participated in this study and out of this 43 (39.1\%) were medical, 37 (33.6\%) were dentist and $30(27.3 \%)$ were nurses. Only 58 students completed the answers of the questionnaire to compare between pre- and post- awareness with the response rate of $52.7 \%$.

Among all, $98.2 \%$ of the students reported that they had information about first aid in the pre-awareness assessment. The source of information differed, and 53.6\% had their information from internet website.

Among all, 79.1\% thought their information is not sufficient. 69 of the student agreed that first aid can save victim's life. $16.4 \%$ of the student answered that they had the ability to do first aid in case of emergency situation and $72.7 \%$ knew Red Crescent number (Figure 1 and Table 1).

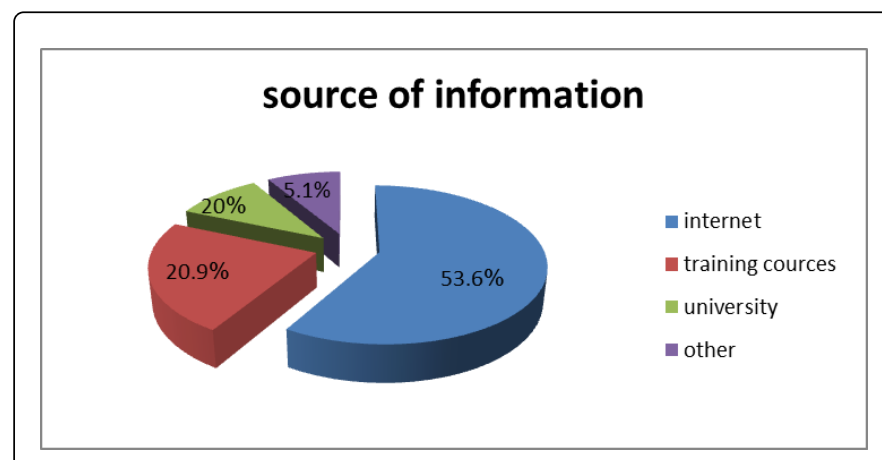

Figure 1: The source of information about first aid among the participant students.

\begin{tabular}{|c|c|c|}
\hline Question & $\begin{array}{l}\% \text { of } \\
\text { right answer }\end{array}$ & $\begin{array}{l}\% \text { of } \\
\text { wrong answer }\end{array}$ \\
\hline Do you have any information about first aid skill? & $98.2 \%$ & $1.8 \%$ \\
\hline Do you think the first aid has rule to save the victim's live? & $69.1 \%$ & $30.9 \%$ \\
\hline Do you think that your knowledge is sufficient? & $20.9 \%$ & $79.1 \%$ \\
\hline Do you know the Saudi emergency call number? & $72.7 \%$ & $27.3 \%$ \\
\hline Do you think you have the ability to do first aid in emergency case? & $16.4 \%$ & $83.7 \%$ \\
\hline What is the first thing you should do before you consider administering First Aid? & $37.3 \%$ & $62.7 \%$ \\
\hline What should you do if someone is unconscious and breathing to help him keep the airway open? [2] & $68.2 \%$ & $31.8 \%$ \\
\hline What should you do if someone is unconscious and not breathing? [2] & $68.2 \%$ & $31.8 \%$ \\
\hline The recovery position is often utilized for casualties but what is its main advantage being? & $64.5 \%$ & $35.4 \%$ \\
\hline How to help someone bleeding from a wound? [2] & $47.3 \%$ & $52.7 \%$ \\
\hline What should you do if case of fracture? [2] & $89.1 \%$ & $10.9 \%$ \\
\hline What is the proper thing you have to do in case of burn? [2] & $73.6 \%$ & $26.4 \%$ \\
\hline What should you do to help someone who is choking? & $75.5 \%$ & $24.5 \%$ \\
\hline What should you do in case of epistaxis? & $55.5 \%$ & $44.5 \%$ \\
\hline What is the best course of action if we witness a casualty having a seizure? & $70.9 \%$ & $29.1 \%$ \\
\hline What should you do to help victims with asthmatic attack? [2] & $68.2 \%$ & $31.9 \%$ \\
\hline If someone is having a hypoglycemic attack, what should you do? & $95.5 \%$ & $4.5 \%$ \\
\hline What the important information you have to know in case of swallow poison or harmful substance? [2] & $83.6 \%$ & $16.4 \%$ \\
\hline
\end{tabular}

Table 1: Showing the 110 student's answer before awareness presentation.

In pre- awareness study which included 110 students, the wrong reflects on skills and attitude of how to manage various emergency case were shown as in first thing providers should do before consider administering first aid $33.6 \%$ were answered to request for an 
ambulance to attend, $29.1 \%$ answered to check to ensure the casualty is stable.

In case of loss of consciousness and if the victim can breathe, 30\% tended to make sure nothing is obstructing the airway.

On other side, if victim has loss of consciousness and cannot breathe, $19.1 \%$ ambulance was called and waited for the paramedics to arrive. $12.7 \%$ thought to call ambulance and put victim in recovery position.

In case of recovery position $30.9 \%$ thought it is a good stable position which can easily monitor a casualty.

In case of bleeding due to injury $52.7 \%$ thought to remove any foreign body from site of bleeding, $6.4 \%$ tended to dress the bone fracture and $4.5 \%$ were tended to ask about pain.

In case of burns, $26.4 \%$ tended to wipe the burn with antiseptic wipes. In case of choking $20.9 \%$ inserted the finger to the back of the victim's throat trying to dislodge the foreign body.

In epistaxis $24.5 \%$ thought to make casualty lean backward and pinch the nose, $20 \%$ thought to put a cotton in nose and breath from the mouth.

In epilepsy management, $23.6 \%$ answered that restrain the victim.

In asthmatic attack $25.5 \%$ thought the victim has to sit in comfortable position and breathing into a paper bag.

In hypoglycemic attack $0.9 \%$ tended to give the victim a low-calorie drink. If victim ingests a toxic substance $9.1 \%$ were thought to ask what those materials have taken, when and why (Figure 2).

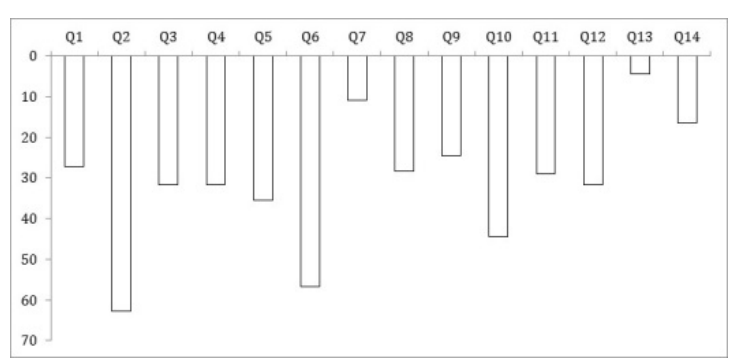

Figure 2: The percentage of the wrong pre-awareness answers about first aid management. Q1 Red crescent number; Q2 The first thing should do before consider administering first aid; Q3 Is unconscious and breathing; Q4 Is unconscious and they are not breathing; Q5 The advantage of recovery position; Q6 Someone is bleeding from a wound; Q7 Broken a leg; Q8 Someone who has a burn; Q9 Someone who is choking; Q10 Bleeding from a nose; Q11 Action if a casualty having a seizure; Q12 Someone Has Asthma Attack; Q13 Someone has a hypoglycemic attack; Q14 A person has swallowed poison.

The comparisons between pre- and post- awareness presentation about first aid study which include 58 female students, 33 (56.9\%) were medical, 19 (32.8\%) were dentist and $6(10.3 \%)$ were nurses (Figure 3 ).

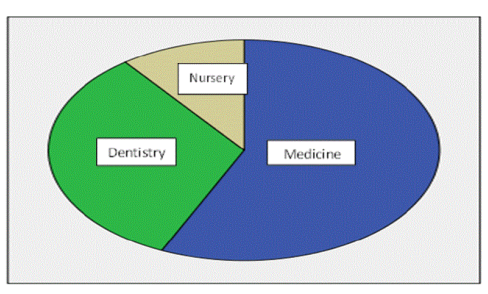

Figure 3: The distribution of the participant students.

Among all, $96.6 \%$ of students answered they had information regarding first aid before awareness compared to one hundred percent after awareness $(\mathrm{p}=0.15)$, in spite of this large percentage, their answers about dealing with emergency situations showed the deficient in their knowledge.

$77.6 \%$ of the student still thought that first aid can save victim's live ( $p=0.84$ ), even in those who's management situation improved by $50 \%$ and became sufficient about first aid (15.5\% pre vs. $65.5 \%$ post, $\mathrm{P}$ $=0.00$ ).

The improvement was $55 \%$ of the students who became more familiar to do first aid in emergency case after awareness about the technique (pre $20.7 \%$ vs. $75.9 \%$ post, $p=0.000$ ), and $20 \%$ of them became more alert about Red Crescent number (pre $67.2 \%$ vs. post $96.6 \%, \mathrm{p}=0.000$ ). $46 \%$ of the students didn't know that they have to check for any hazards and dangers before going to do first aid, after awareness the observed improvement was $24 \%$ (pre $46.6 \%$ vs. post $70.7 \%, \mathrm{p}=0.005$ ).

In case of loss of consciousness while the victim can breathe the observed improvement was $22 \%$ became more alert to check first if the victim is breathing or not then call the ambulance for help $(62.1 \%$ pre vs. $84.5 \%$ post, $\mathrm{p}=0.003)$. On the other hand, if victim losses his consciousness and cannot breathe $24 \%$ knew that they have to call ambulance first then push in the center of the chest 30 compressions as a regular rate $(72.4 \%$ pre vs. $96.6 \%$ post, $\mathrm{p}=0.002)$.

In case of recovery position which is to make sure that airway is patent the observed improvement was $24 \%$ became more alert than those before awareness (pre $63.8 \%$ vs. $87.9 \%$ post, $p=0.117$ ). In case of bleeding due to injury $53.4 \%$ were aware that direct pressure is applied and the injured limb is raised above the level of the heart, postawareness became $77.6 \%(p=0.009)$. In case of bone fracture $98.3 \%$ knew to support the affected limb using a cushion or some clothing, compared to those before awareness $84.5 \%(\mathrm{p}=0.009)$. In case of burns $65.5 \%$ pre- awareness knew to cool the burn under cold water for 10 minutes which helps to stop the burning process, while $86.2 \%$ post- awareness choose the correct answer $(\mathrm{p}=0.004)$.

In case of choking $67.2 \%$ knew to hit the victim firmly on their back between the shoulder to dislodge the foreign body, while in postawareness $75.9 \%$ choose the correct option $(\mathrm{p}=0.517)$. In case of epistaxis $57 \%$ became more oriented that the victim should pinch the nose and lean forward (20.7\% pre vs. $77.6 \%$ post, $\mathrm{p}=0.00)$.

In epilepsy management $87.9 \%$ post- awareness answered that the victim should be placed in a safe place and not to restrict them, while in pre- awareness $60.3 \%$ were knew the correct answer $(p=0.001)$. In asthmatic attack the person should take his medication and sit in a 
Page 4 of 5

comfortable position, $63.8 \%$ pre-awareness choose the correct answer while in post-awareness they became $87.9 \%(\mathrm{p}=0.002)$.

In hypoglycemic attack $93.1 \%$ knew that the victim had to be given a sugary drink or food to raise the blood glucose level, in comparison between pre- and post- awareness it showed a significant difference; post-awareness was $98.3 \%(\mathrm{p}=0.024)$.
In case of ingestion of toxic substance $84.5 \%$ knew that it should be important to ask about the cause that made the victim ingest those material, time of ingestion and amount of the substance, while in postawareness $93.1 \%$ became more alert $(\mathrm{p}=0.18)$ but didn't show significant difference (Table 2).

\begin{tabular}{|c|c|c|c|c|}
\hline Question & Pre answer \% & Post answer\% & $P$ value & 95\% Confidence Interval \\
\hline Do you have any information about first aid skill? & $96.60 \%$ & $100 \%$ & 0.527 & $-0.014-0.083$ \\
\hline Do you think the first aid has rule to save the victim's live? & $77.60 \%$ & $77.60 \%$ & 0.84 & $-0.191-0.157$ \\
\hline Do you think that your knowledge is sufficient? & $15.50 \%$ & $65.50 \%$ & 0.157 & $0.335-0.665$ \\
\hline Do you know the Saudi emergency call number (red crescent)? & $67.20 \%$ & $96.60 \%$ & 0 & $0.163-0.423$ \\
\hline Do you think you have the ability to do first aid in emergency case? & $20.70 \%$ & $75.90 \%$ & 0 & $0.425-0.851$ \\
\hline $\begin{array}{l}\text { What is the first thing you should do before you consider administering First } \\
\text { Aid? }\end{array}$ & $46.60 \%$ & $70.70 \%$ & 0.005 & $-0.666-0.127$ \\
\hline $\begin{array}{l}\text { What should you do if someone is unconscious and breathing to help him keep } \\
\text { the airway open? [2] }\end{array}$ & $62.10 \%$ & $84.50 \%$ & 0.003 & $0.152-0.710$ \\
\hline What should you do if someone is unconscious and not breathing? [2] & $72.40 \%$ & $96.60 \%$ & 0.002 & $0.128-0.527$ \\
\hline $\begin{array}{l}\text { The recovery position is often utilized for casualties but what is its main } \\
\text { advantage being? }\end{array}$ & $63.80 \%$ & $87.90 \%$ & 0.117 & $-0.036-0.312$ \\
\hline How to help someone bleeding from a wound? [2] & $53.40 \%$ & $53.40 \%$ & 0.009 & $-0.421-0.062$ \\
\hline What should you do if case of fracture? [2] & $84.50 \%$ & $98.30 \%$ & 0.009 & $-0.361--0.053$ \\
\hline What is the proper thing you have to do in case of burn? [2] & $65.50 \%$ & $86.20 \%$ & 0.004 & $0.148-0.714$ \\
\hline What should you do to help someone who is choking? & $67.20 \%$ & $75.90 \%$ & 0.517 & $-0.215-0.421$ \\
\hline What should you do in case of epistaxis? & $20.70 \%$ & $77.60 \%$ & 0 & $-0.516-0.036$ \\
\hline What is the best course of action if we witness a casualty having a seizure? & $60.30 \%$ & $87.90 \%$ & 0.001 & $0.222-0.847$ \\
\hline What should you do to help victims with asthmatic attack? [2] & $63.80 \%$ & $87.90 \%$ & 0.002 & $0.195-0.805$ \\
\hline If someone is having a hypoglycemic attack, what should you do? & $93.10 \%$ & $98.30 \%$ & 0.024 & $0.012-0.161$ \\
\hline $\begin{array}{l}\text { What the important information you have to know in case of swallow poison or } \\
\text { harmful substance? [2] }\end{array}$ & $84.50 \%$ & $93.10 \%$ & 0.18 & $-0.057-0.299$ \\
\hline
\end{tabular}

Table 2: Comparison between the 58 students answers to the questions before and after the awareness presentation.

\section{Discussion}

At the best of our knowledge, no similar studies regarding awareness of first aid measures among medical students have been done in Saudi Arabia before. Other studies were conducted to estimate the knowledge and attitude of medical students about the basic life support (BLS) [3], and another study studied first aid measures among secondary school students of Saudi Arabia [4-7].

The pre- awareness results of this study showed that the majority of the female students (98.2\%) thought that they had previous knowledge about first aid, only $16.4 \%$ reported to have the ability to do first aid in emergency case. A Peruvian study reported that $52.5 \%$ of medical students had prior training in management of medical emergencies; however, $60.4 \%$ of them had poor knowledge about first aid. Abd ElHay et al. [8] determined that all students had poor mean score of knowledge and practice regarding first aid and basic life support.
In this study, the knowledge of first aid management in suspected bone fractures was about $89.1 \%$ and in bleeding was $47.3 \%$, similar to studies in Mangalore in South India was $12.5 \%$ for both fracture and bleeding management [3]. A study in Kuwait University for knowledge about wound bleeding revealed $42.3 \%$ and for bone fracture was $59.6 \%$ [5]. The first aid management of burns was known correctly by $73.6 \%$ students in this study, as against $23.2 \%$ in an Irish study, $13.8 \%$ in south Indian study and $32.6 \%$ in Kuwait University. Analysis of knowledge about first aid management of epistaxis $55.5 \%$ had good knowledge, against 13.8\% in Mangalore University study in South India [3].

First aid followed by accidental choking by a foreign body was good in $75.5 \%$ in this study against $43.6 \%$ cases in the Karachi based study, $53.4 \%$ in the Peruvian study and $13.2 \%$ in South Indian study [3]. This study also reported that $83.6 \%$ of the students had good knowledge of first aid management in cases of accidental ingestion of poisons as against $15.8 \%$ in study of South India study. 
Page 5 of 5

With respect to correct management of convulsions, $70.9 \%$ was good in this study, as compared to $24.8 \%$ medical students in the Karachi and $13.8 \%$ students in South Indian study. In correct management of recovery position, $24.8 \%$ medical students in the Karachi study knew of recovery position as against $64.5 \%$ students in this study. The majority of students in this study knew management of victims with hypoglycemic attack sufficiently with rate of $95.5 \%$ compared to $61 \%$ in Kuwait University study. Victims in case of unconsciousness and breathing by $68.2 \%$ against $16.5 \%$ in Kuwait University study.

After the awareness program which was submitted to the students in this study, significant improvement was shown in the knowledge of the majority of the first aid questions. This is in agreement with Abd ElHay et al. [8] and Bolling et al. [9] who reported that first aid training resulted in improvement of the knowledge and attitude of the students. Some knowledge didn't show statistically improvement and this could be attributed that regular workshops were needed for the students and refresh their knowledge continuously.

\section{Limitations of the Study}

The male student was not included in this study because they are in separate building. Regular workshops with the students were not possible due to the authors and the student's load of their academic courses.

\section{Conclusion}

This study showed the inadequate knowledge about first aid and lacked the main concept and technique of first aid among the female medical students. The efficiency of the awareness education program was indicated by the improvement in dealing with various emergency situations in post- awareness assessment.

\section{Recommendations}

First aid training program should be added in the curriculum of the health science students at Taibah University to improve the knowledge and basic skills about first aid.

\section{Acknowledgment}

Acknowledge to Prof. Magda Hassanein Metwally Youssef for the support and help during this study. Also, the authors acknowledge the student from College of Medicine, Density and Nursery for their participation.

\section{References}

1. Swetha C, Suchitra M N, Sahana, B N (2015) A Study On Assessment Of Knowledge Attitude And Practices Regarding First Aid Among Nursing Students. Int J Curr Res 7: 16873-16875.

2. http://www.redcross.org.uk/What-we-do/First-aid/Everyday-First-Aid

3. Joseph N, Kumar GS, Babu YPR, Nelliyanil M, Bhaskaran U (2014) Knowledge of First Aid Skills Among Students of a Medical College in Mangalore City of South India. Ann Med Health Sci Res 4: 162-166.

4. Abbas A, Bukhari SI, Ahmad F (2011) Knowledge of first aid and basic life support amongst medical students: a comparison between trained and un-trained students. J Pak Med Assoc 61: 613-616.

5. Al-Khamees N (2006) A field study of first aid knowledge and attitudes of college students in Kuwait University. College Student Journal Publisher 40: E197500.

6. Alanazi A, Alsalmeh M, Alsomali O, Almurshdi AM, Alabdali A, et al. (2014) Poor Basic Life Support Awareness among Medical and College of Applied Medical Sciences Students Necessitates the Need for Improvement in Standards of BLS Training and Assessment for Future Health Care Providers. Middle-East Journal of Scientific Research 21: 848-854.

7. Mobarak A S, Afifi R M, Qulali A (2015) First Aid Knowledge and Attitude of Secondary School Students in Saudi Arabia. Health 7: 1366-1378.

8. Abd El-Hay SA, Ibrahim NA, Hassan LA (2015) Effect of Training Program Regarding First Aid and Basic Life Support on the Management of Educational Risk injuries among Students in Industrial Secondary Schools. IOSR Journal of Nursing and Health Science 4: 32-43.

9. Bollig G, Wahl HA, Svendsen MV (2009) Primary School Children are Able to Perform Basic Life-Saving First Aid Measures, Resuscitation M J 80: 689-692. 